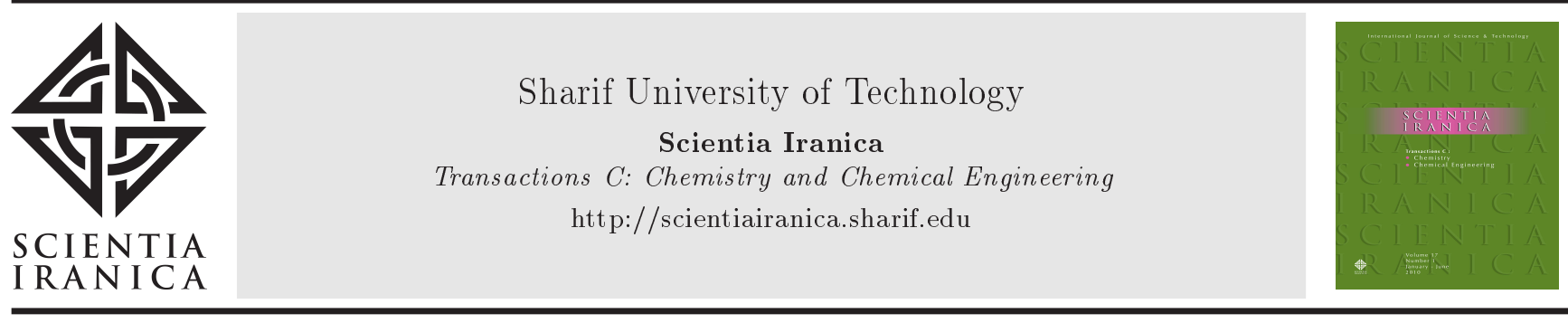

\title{
A comprehensive study of the leaching behavior and dissolution kinetics of copper oxide ore in sulfuric acid lixiviant
}

\author{
B. Bayati, A. Azizi*, and M. Karamoozian \\ Faculty of Mining, Petroleum and Geophysics, Shahrood University of Technology, Shahrood, Iran.
}

Received 20 September 2017; received in revised form 20 December 2017; accepted 27 January 2018

\author{
KEYWORDS \\ Copper oxide ore; \\ Leaching behavior; \\ Recovery; \\ Kinetics; \\ Shrinking core model; \\ Optimization.
}

\begin{abstract}
The leaching behavior of an Iranian copper oxide ore in sulphuric acid was investigated in detail to evaluate the influence of various factors, to optimize the dissolution conditions, and to determine the kinetics of the leaching. The results indicated that the increase in the leaching time and temperature enhanced the leaching rate of copper. The leaching rate increased up to a certain value with increasing the agitation rate, acid concentration, and liquid/solid ratio and, then, reduced with a further increment. Agitaion rate had the highest influence on the dissolution of copper. The $3 \mathrm{D}$ response surface graphs confirmed the interactive effects of sulphuric acid concentration, agitation speed, and liquid/solid ratio with temperature. About $91 \%$ copper content was leached in $\sim 13 \%$ sulphuric acid concentration, stirring rate of $600 \mathrm{rpm}$, liquid/solid ratio of $10 \mathrm{~mL} / \mathrm{g}$, and $50^{\circ} \mathrm{C}$ after 80 min leaching. The dissolution kinetics was examined according to heterogeneous models. The shrinking core model, which considers the rate control by diffusion through the product layer, was found appropriate enough to describe the dissolution of copper in sulphuric acid solution. The activation energy was obtained to be $26.699 \mathrm{~kJ} / \mathrm{mol}$, and the equation representing the leaching kinetics of copper based on the diffusion-controlled model was found to be $1-3(1-x)^{2 / 3}+2(1-x)=161.97 \times \exp \left(-26.699 \times 10^{3} / 8.314 \times T\right) \times t$. (C) 2018 Sharif University of Technology. All rights reserved.
\end{abstract}

\section{Introduction}

Copper, as one of the most common and valuable metals applied in industrial fields and every aspects of life, is found mainly in nature in the form of sulfide and oxide minerals such as chalcopyrite, chalcocite, malachite, bornite, azurite, chrysocolla, etc. [1-5]. The copper produced from sulfide and oxide copper ores is extracted through pyrometallurgical and hydrometallurgical processes, respectively. Leaching is typically the first step of any hydrometallurgical process [6]. During the leach-

*. Corresponding author. Fax: +98 2332395509

E-mail address: azizi.asghar22@yahoo.com (A. Azizi)

doi: $10.24200 /$ sci.2018.5226.1154 ing process of copper oxidized ores, sulfuric acid leaching is viewed as the most viable and versatile process. The most common copper oxide minerals, such as azurite $\left(\mathrm{Cu}_{3}(\mathrm{OH})_{2}\left(\mathrm{CO}_{3}\right)_{2}\right)$, malachite $\left(\mathrm{Cu}_{2}(\mathrm{OH})_{2} \mathrm{CO}_{3}\right)$, and copper oxide $(\mathrm{CuO})$, can be dissolved by sulphuric acid according to the reactions given below [7]:

$$
\begin{gathered}
\mathrm{Cu}_{3}(\mathrm{OH})_{2}\left(\mathrm{CO}_{3}\right)_{2}+3 \mathrm{H}_{2} \mathrm{SO}_{4} \rightarrow 3 \mathrm{CuSO}_{4}+2 \mathrm{CO}_{2} \\
+4 \mathrm{H}_{2} \mathrm{O} \\
\mathrm{Cu}_{2}(\mathrm{OH})_{2} \mathrm{CO}_{3}+2 \mathrm{H}_{2} \mathrm{SO}_{4} \rightarrow 2 \mathrm{CuSO}_{4}+\mathrm{CO}_{2}+3 \mathrm{H}_{2} \mathrm{O} \\
\mathrm{CuO}+\mathrm{H}_{2} \mathrm{SO}_{4} \rightarrow \mathrm{CuSO}_{4}+\mathrm{H}_{2} \mathrm{O}
\end{gathered}
$$

The dissolution of sulfide and oxide minerals is important in a wide range of fields, including minerals 
Table 1. Results of the XRF analysis; chemical composition of the ore sample (mass fraction, \%).

\begin{tabular}{ccccccccc}
\hline Composition & $\mathbf{K}_{\mathbf{2}} \mathbf{O}$ & $\mathbf{N a}_{\mathbf{2}} \mathbf{O}$ & $\mathbf{M n O}$ & $\mathbf{M g O}$ & $\mathbf{C a O}$ & $\mathbf{F e}_{2} \mathbf{O}_{3}$ & $\mathbf{A l}_{\mathbf{2}} \mathbf{O}_{\mathbf{3}}$ & $\mathbf{S i O}_{\mathbf{2}}$ \\
\hline w/w (\%) & 2.41 & 2.03 & 0.14 & 4.46 & 24.25 & 6.96 & 8.59 & 37.04 \\
Composition & $\mathrm{TiO}_{2}$ & $\mathrm{SrO}$ & $\mathrm{ZnO}$ & $\mathrm{CuO}$ & $\mathrm{SO}_{3}$ & $\mathrm{Cr}_{2} \mathrm{O}_{3}$ & $\mathrm{P}_{2} \mathrm{O}_{5}$ & \\
\hline w/w (\%) & 0.66 & 2.26 & 0.19 & 5.89 & 4.40 & 0.05 & 0.35 & \\
\hline
\end{tabular}

processing, hydrometallurgy, geochemistry, and materials science. Knowledge of the mechanism of dissolution can be of assistance in the design, optimization, and intensification of processes for the extraction of copper [8]. For this reason, a great deal of attention has been focused on the study of the behavior and kinetics of leaching. Researches on leaching behavior and kinetics of copper oxide ores have been extensively conducted by different lixiviants including mineral acids, such as $\mathrm{HCl}, \mathrm{H}_{2} \mathrm{SO}_{4}$, and $\mathrm{HNO}_{3}$ [7,9-11]; organic acids, such as citric acid and lactic acid [11-13]; chlorine [14]; ammonium hydroxide or ammonium salts including ammonium chloride, ammonium sulfate, ammonium nitrate, ammonium citrate, ammonium acetate, etc. [2,15-24]; and alkaline glycine solutions [25]. In addition, Deng et al. [26] investigated extraction and dissolution kinetics of copper from a malachite ore by Sulfamic Acid (SA). They indicated that the leaching rate increased with decreasing particle size and increasing concentration, reaction temperature, and stirring speed. In addition, the dissolution kinetics follows a shrinking core model with three-dimensional diffusion as the rate-controlling step. Sun et al. [27] investigated the leaching kinetic behavior of copper from low-grade copper oxide ore. They reported that the leaching process by $\mathrm{H}_{2} \mathrm{SO}_{4}$ can be described with a reaction model of shrinking core, and the leaching process can be divided into three stages in the system investigated. Moreover, the leaching efficiency of copper can reach up to a level higher than $90 \%$.

Although many experimental studies have been performed to gain a better understanding of the leaching process and its operation, there are still few researches concerned with the aim of optimizing the process and kinetics modelling. An accurate understanding of the leaching kinetics helps to interpret the complex behavior of leaching process. Thus, this study aims to investigate and discuss the leaching kinetics and dissolution parameters of oxide copper ore in sulphate solution. In this study, the dissolution kinetics is examined according to the shrinking core models, and the best kinetics model is chosen to describe the leaching process of copper oxide ore. Moreover, an experimental design technique, Response Surface Method (RSM), is employed to model, optimize, and evaluate the effects and interactions of the influential parameters on recovery of copper.

\section{Experimental descriptions}

\subsection{Materials}

Copper oxide ore was collected from the Fariman copper mine in Khorasan-e-Razavi province, Iran. The samples were prepared after two stages of laboratory comminution including crushing (jaw crusher) and milling (ball mill). Thereafter, representative samples were analyzed to characterize the main chemical compositions by X-Ray Fluorescence (XRF), in which the results are presented in Table 1 . In addition, the phases of sample were characterized by XRD, in which the main phases identified from the XRD pattern for oxide copper included malachite and azurite.

\subsection{Leaching experiments}

Leaching experiments were carried out in a beaker of $500 \mathrm{~mL}$ which was heated on a hot plate equipped with a digitally controlled magnetic stirrer and a thermometer for temperature control under different conditions. A representative sample $(3 \mathrm{~g})$ was selected for each leaching test. The leaching liquor was prepared using distilled water and the analytical grade $\mathrm{H}_{2} \mathrm{SO}_{4}$ reagent in predetermined concentrations. Then, based on the desired liquid-to-solid ratio, a definite volume of the solution was poured into the beaker at the required temperature. When the solution reached the desired temperature, sample was added into the beaker and the contents of the beaker were stirred at a certain speed. A 5-mL sample was accurately withdrawn at regular intervals during the reaction and was immediately filtered. Then, the solution was analyzed using a unicam Atomic Absorption Spectrometry (AAS) [28,29]. The amounts of copper leached were calculated via the following equation:

$$
R=\frac{M_{1}}{M_{0}} \times 100,
$$

where $R$ is the recovery percentage of copper and $M_{0}$ and $M_{1}$ are the mass of copper passing to the solution and mass of copper in the ore sample, respectively.

\section{Results and discussion}

\subsection{Effect of stirring speed}

The effect of stirring rate on the leaching of copper was investigated using different agitation speeds that 


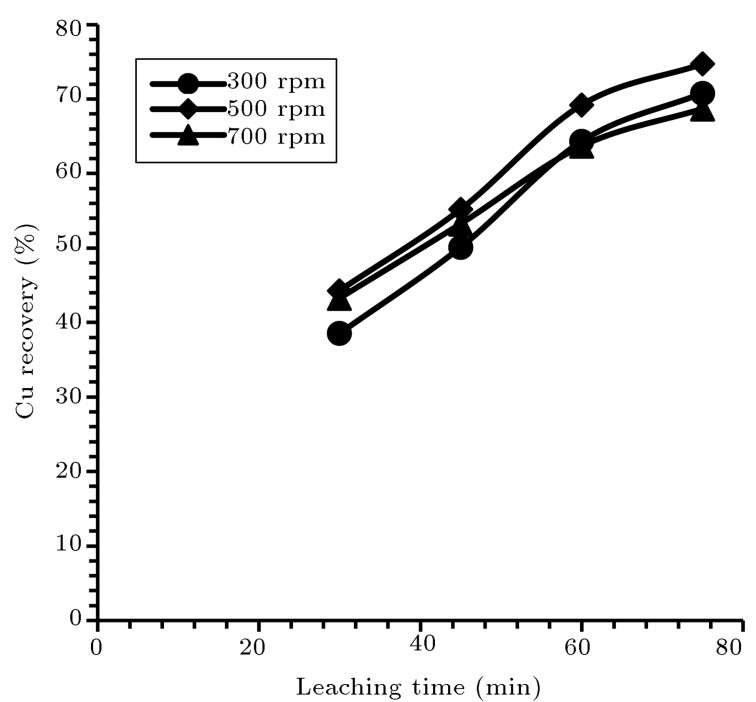

Figure 1. Effect of stirring speed on the dissolution of copper oxide ore.

ranged from 200 to $700 \mathrm{rpm}$. While conducting experiments, the values of other experimental parameters were kept constant at $30^{\circ} \mathrm{C}$, liquid/solid ratio of $10 \mathrm{~mL} / \mathrm{g}$, and acid concentration of $10 \%$. The results obtained are plotted in Figure 1. The results indicate that the agitation has a more pronounced effect on the dissolution of copper with $\mathrm{H}_{2} \mathrm{SO}_{4}$. As shown in Figure 1, the maximum copper leaching rate $(74.43 \%)$ was obtained at stirring speed of $500 \mathrm{rpm}$ after 75 min of dissolution. An increase in stirring speed usually increases the leaching rate of copper due to the suspension of the mineral particles and decreases the thickness of the mass transfer boundary layer on the surface of the particle [30]. Based on this behavior, leaching can be also influenced by a specific range of stirring speeds. In kinetic terms, a higher stirring speed accelerates diffusion and enables homogeneous mixing of the liquid and solid phases in the reactor, which can promote the reaction [13]. Thus, a stirring speed of $500 \mathrm{rpm}$ was used thereafter to assure that the leaching reaction was not under external diffusion control. However, the diffusion as the controlling step cannot be eliminated, and the leaching process can be controlled by the surface reaction, or the solid internal diffusion, or both of them.

\subsection{Effect of Liquid-to-Solid (L/S) ratio}

To study the effect of pulp density or Liquid-toSolid $(\mathrm{L} / \mathrm{S})$ ratio on the dissolution rate, experiments were performed with three different ratios $(6,10$, and $20 \mathrm{~mL} / \mathrm{g}$ ). During the experiments, the leaching temperature, sulphuric acid concentration, and agitation rate were kept constant at $30^{\circ} \mathrm{C}, 10 \%$, and $500 \mathrm{rpm}$, respectively. Data shown in Figure 2 indicate that the dissolution rate of copper increases with increasing $\mathrm{L} / \mathrm{S}$ ratio to a certain amount and, then, reduces with a further increment; moreover, a Liquid/Solid (L/S)

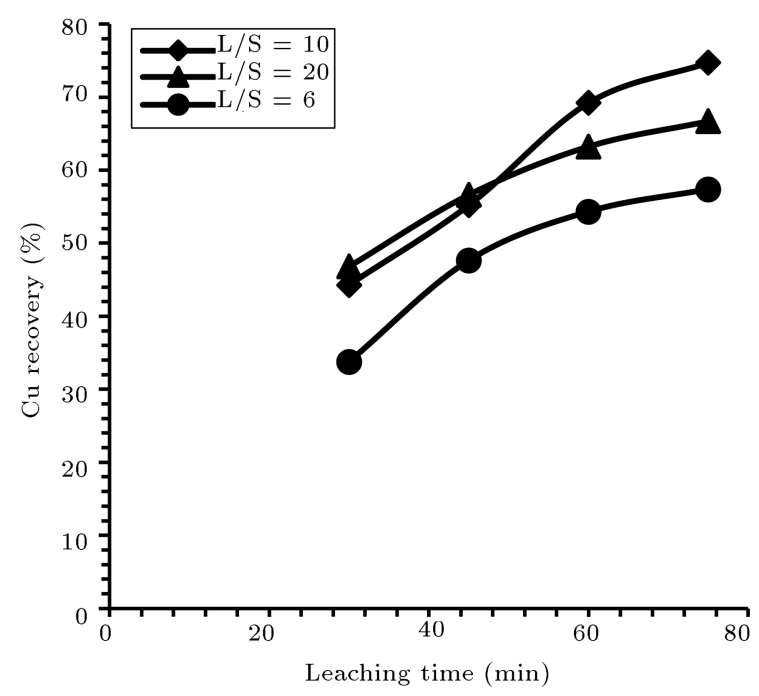

Figure 2. Effect of liquid-to-solid (L/S) ratio on the dissolution of copper oxide ore.

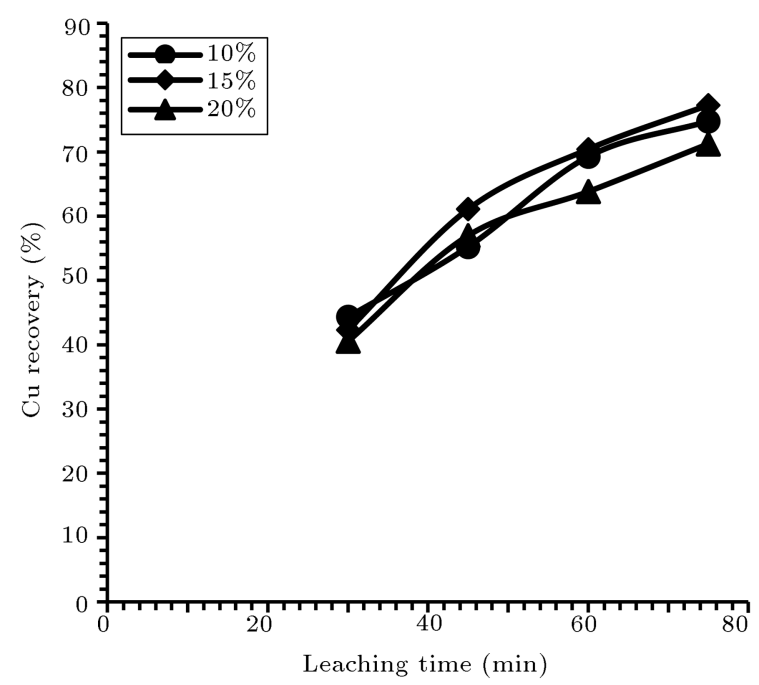

Figure 3. Effect of sulphuric acid concentration on the dissolution of copper oxide ore.

ratio of $10 \mathrm{~mL} / \mathrm{g}$ is found to be optimal for leaching of copper using $\mathrm{H}_{2} \mathrm{SO}_{4}$. This can be explained in a way that the leaching agent is in excess of the calculated amount for the extraction of copper. After $75 \mathrm{~min}$ of dissolution, the amounts of copper extracted from the oxide ore were $57.37,74.73$, and $66.71 \%$ at $\mathrm{L} / \mathrm{S}$ ratios of 6,10 , and $20 \mathrm{~mL} / \mathrm{g}$, respectively.

\subsection{Effect of acid concentration}

To investigate the effect of acid concentration on the leaching rate of copper, experiments were performed with $\mathrm{H}_{2} \mathrm{SO}_{4}$ at a temperature of $30^{\circ} \mathrm{C}$, stirring rate of $500 \mathrm{rpm}, \mathrm{L} / \mathrm{S}$ of $10 \mathrm{~mL} / \mathrm{g}$, and contact time of $75 \mathrm{~min}$. In this study, the effect of acid concentration was evaluated by regulating the concentration to 10,15 , and $20 \%$, in which the results are given in Figure 3 as a fraction of leached copper versus leaching time. It was observed that the dissolution rate of copper increased 
meaningfully by increasing the $\mathrm{H}_{2} \mathrm{SO}_{4}$ concentration up to a certain value and, thereafter, reduced. This behavior takes place due to certain variations in the leaching mechanism and varying acid concentrations (for example, mechanism varying from surface chemical reaction to diffusion). The maximum dissolution of copper was obtained as $77.25 \%$ with acid concentration of $15 \%$. In addition, this could be because copper particles exposed to sulphuric acid reduced after a certain time and in a certain concentration (75 min and $15 \%$ in this experiment), and, finally, decreased the recovery of copper. On the other hand, there are a lot of $\mathrm{CaO}$ and $\mathrm{SiO}_{2}$ in the copper oxide ore in this work; consequently, the silica gel can be produced in a sulfuric acid leaching system, which may increase acid consumption.

\subsection{Effect of temperature}

The effect of leaching temperature on copper leaching yield was evaluated in an acid concentration of $15 \%$, $\mathrm{L} / \mathrm{S}$ ratio of $10 \mathrm{~mL} / \mathrm{g}$, and stirring speed of $500 \mathrm{rpm}$. The result shown in Figure 4 indicates that the dissolution rate increases with an increase in leaching temperature from $74.73 \%$ at $30^{\circ} \mathrm{C}$ to $87.02 \%$ at $50^{\circ} \mathrm{C}$ in $75 \mathrm{~min}$, for example. As expected, the leaching temperature played an important role in dissolution. However, the impact of temperature on the copper leaching rate is not very large during contact time of 75 min (from 40 to $50^{\circ} \mathrm{C}$ ), suggesting that the dissolution process may be controlled by diffusion reaction. In fact, it is observed that with a further increase of the temperature and time, the leaching rate of copper increases intermediately.

\subsection{Identification of the leaching mechanism}

The reaction occurring between copper oxide ore particles and sulphate solution during the leaching process is a typical example of heterogeneous liquid-solid

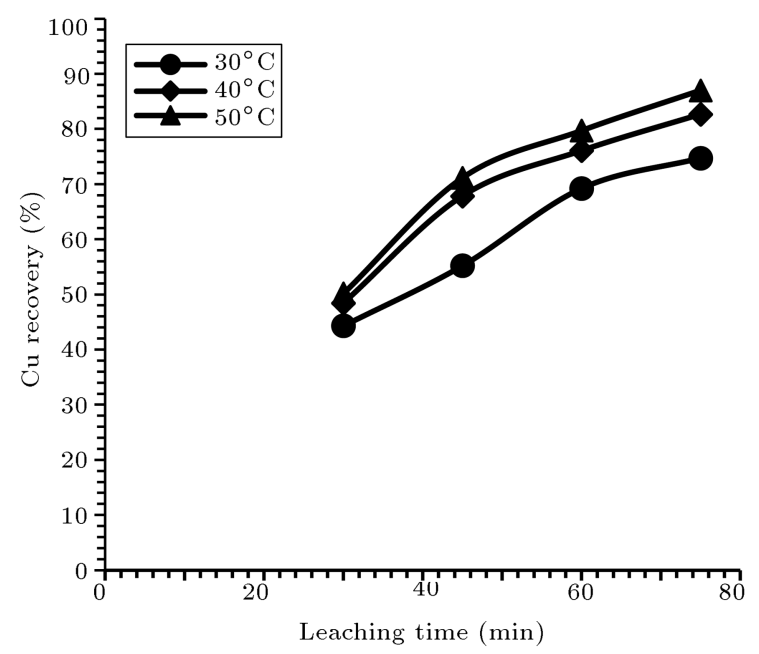

Figure 4. Effect of leaching temperature on the dissolution of copper oxide ore. reactions. In heterogeneous reaction systems, most reactions follow a Shrinking Core Model (SCM) which approximates the dissolution of real particles [31]. According to this model, it can be concluded that the leaching process in $\mathrm{H}_{2} \mathrm{SO}_{4}$ solution involves:

(i) Transport of $\mathrm{H}_{2} \mathrm{SO}_{4}$ from the bulk solution to the particle surface;

(ii) Diffusion of $\mathrm{H}_{2} \mathrm{SO}_{4}$ through the solid residual layer from the particle surface to the surface of unreacted core;

(iii) Reaction between $\mathrm{H}_{2} \mathrm{SO}_{4}$ and oxide ore on the surface of the unreacted core;

(iv) Diffusion of the resultants through the solid residual layer from the reaction interface to the particle surface;

(v) Transport of the resultants from the particle surface to the bulk solution $[28,29,32]$.

Generally, this model expressed below described equations $[11,19,31]$. This model assumes that the reaction between solid and liquid reactants occurs on the outer surface of the solid particle, and the reacting particles are spherical whose size does not change during reaction [23].

If the leaching rate of the particle is controlled by liquid film diffusion, the kinetic equation can be expressed as in Eq. (5):

$$
1-(1-x)^{\frac{2}{3}}=k \times t
$$

If the leaching rate is controlled by diffusion through a product layer, the kinetic equation is:

$$
1-3(1-x)^{\frac{2}{3}}+2(1-x)=k \times t .
$$

If the leaching rate is controlled by a surface chemical reaction, the kinetic equation is:

$$
1-(1-x)^{\frac{1}{3}}=k \times t
$$

where $x$ is the fraction of lead reacted, $t$ is the reaction time ( $\min$ or $\mathrm{h}$ ), and $k$ is the apparent rate constant $\left(\min ^{-1}\right.$ or $\left.\mathrm{h}^{-1}\right)$. The rate of the process is controlled by the slowest sequential steps.

To determine the kinetic parameters and ratecontrolling step of copper leaching in the sulphuric acid solution, the data obtained in the leaching experiments were analyzed based on the shrinking core model equations. By applying the rate expression in Eqs. (5)(7) to the experimental data obtained, the apparent rate constants were calculated. To obtain the apparent rate constants of each step, the left sides of Eqs. (5) to (7) were plotted against time, whose results are shown in Figure 5. From the slopes of the straight lines, the apparent rate constants (Figure $5(\mathrm{a})-(\mathrm{c})), k$, 


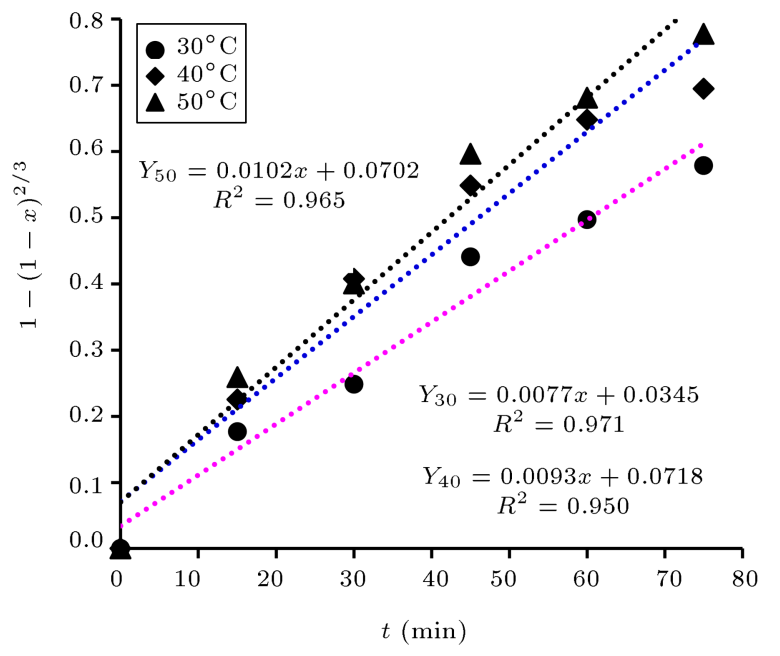

(a)

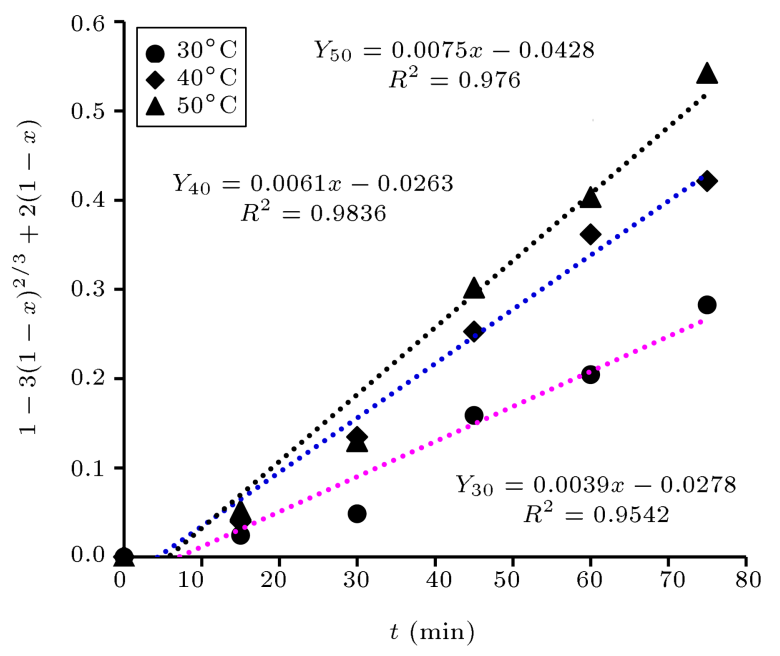

(b)

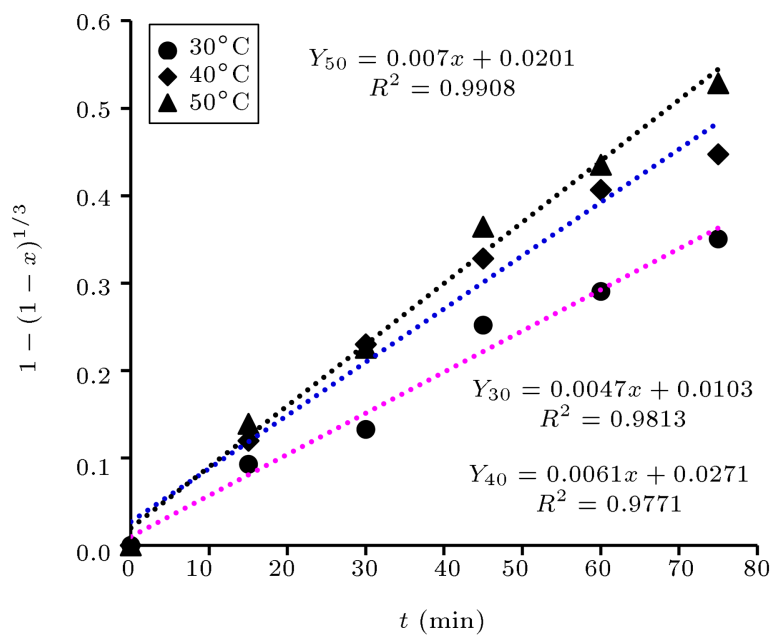

(c)

Figure 5. Plot of the shrinking core models versus leaching time $(t)$ for the dissolution of copper with $\mathrm{H}_{2} \mathrm{SO}_{4}$ : (a) Liquid film diffusion, (b) film diffusion through the ash or product layer, and (c) surface chemical reaction. were evaluated, and the rate constants calculated from the slopes of the straight lines and their correlation coefficients are given in Figure 5.

As observed, all three models have good linear fits and their $R^{2}$ values are close to each other. Therefore, it is difficult to distinguish between these reaction models. Another important parameter that can be used to justify the rate-determining step in hydrometallurgical process is activation energy [33]. Hence, the activation energy describing the temperature dependence of the reaction rate constant was employed to investigate the dissolution kinetics of copper and determine the ratecontrolling step of leaching rate. The activation energy was calculated based on the Arrhenius equation:

$$
k=A \times e^{\frac{-E a}{R \times T}} \Rightarrow \operatorname{Ln}(k)=\operatorname{Ln}(A)-\frac{E a}{R} \cdot \frac{1}{T},
$$

where $k$ is the reaction rate constant $\left(\min ^{-1}\right), A$ is the frequency factor $\left(\mathrm{min}^{-1}\right), E a$ is the activation energy of the reaction $\left(\mathrm{J} . \mathrm{mol}^{-1}\right), R$ is the universal gas constant (8.314. $\left.\mathrm{JK}^{-1} . \mathrm{mol}^{-1}\right)$, and $T$ is the leaching temperature in Kelvin $(\mathrm{K})$.

Arrhenius equation was plotted as $\operatorname{Ln}(k)$ versus $(1 / T)$ for each temperature, and the activation energies were calculated from the slopes of straight lines where the slope is $-E a / R$. For example, the Arrhenius plot $(\mathrm{Ln}(k)$ versus $1 / T)$ of copper dissolution in $\mathrm{H}_{2} \mathrm{SO}_{4}$ solution based on the diffusion models is shown in Figure 6 . The values of activation energies and frequency factor calculated from Arrhenius equation and reaction rate constants are presented in Table 2.

As considered in Table 2, the activation energies calculated for dissolution of copper in sulphuric acid solution based on fluid film diffusion, diffusion through a product layer, and surface chemical reaction are $11.47,26.69$, and $16.25 \mathrm{~kJ} / \mathrm{mol}$, respectively. These small values indicate that the leaching rate is controlled by diffusion process [29,30,34]. In addition, the effects of stirring rate and temperature confirm that a diffusion process controls the dissolution reaction. However, it does not imply that the rate of process is definitely controlled by diffusion through the fluid film or through the product layer. However, the agitation speed had the pronounced effect on the dissolution of copper, and the leachability increased with increasing agitation rate up to $500 \mathrm{rpm}$; in contrast, at stirring speeds exceeding $500 \mathrm{rpm}$, the agitation rate showed a decreasing effect. This indicates that the dissolution process does not seem to be controlled by mass transfer through the liquid film; however, the possible change in solution viscosity may be brought about by silica gel formation in the sulfuric acid leaching system due to the presence of high values of $\mathrm{CaO}(24.25 \%)$ and $\mathrm{SiO}_{2}(37.04 \%)$ in the copper oxide ore investigated. Consequently, the equations representing the kinetics of leaching process of copper oxide ore can be expressed 


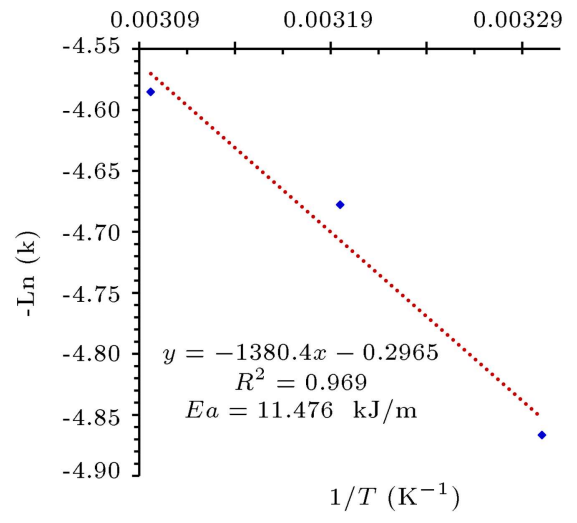

(a)

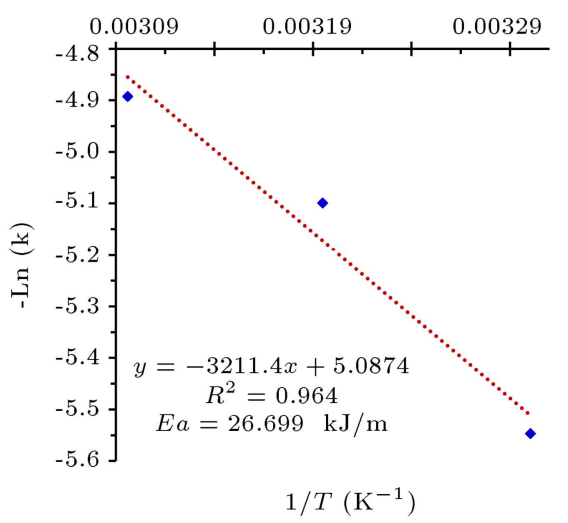

(b)

Figure 6. Arrhenius plot for the dissolution of copper with $\mathrm{H}_{2} \mathrm{SO}_{4}$ based on (a) the liquid film diffusion model and (b) diffusion through the product layer.

Table 2. Arrhenius parameters (activation energy and frequency factor) values and reaction rate constants calculated for the leaching of copper oxide ore in sulphuric solution.

\begin{tabular}{|c|c|c|c|c|}
\hline $\begin{array}{c}\text { Shrinking core } \\
\text { model }\end{array}$ & $\begin{array}{c}\text { Temperature } \\
\left({ }^{\circ} \mathrm{C}\right)\end{array}$ & $\begin{array}{l}\text { Apparent rate constants } \\
\qquad(k), \min ^{-1}\end{array}$ & $\begin{array}{l}\text { Frequency } \\
\quad \text { factor } \\
(A), \min ^{-1}\end{array}$ & $\begin{array}{c}\text { Activation } \\
\text { energy } \\
(\boldsymbol{E a}), \mathrm{kJ} / \mathbf{m o l} \\
\end{array}$ \\
\hline Diffusion through liquid film & $\begin{array}{l}30 \\
40 \\
50\end{array}$ & $\begin{array}{l}0.0077 \\
0.0093 \\
0.0102\end{array}$ & 0.7434 & 11.476 \\
\hline Diffusion through product layer & $\begin{array}{l}30 \\
40 \\
50\end{array}$ & $\begin{array}{l}0.0039 \\
0.0061 \\
0.0075\end{array}$ & 161.97 & 26.699 \\
\hline Surface chemical reaction & $\begin{array}{l}30 \\
40 \\
50\end{array}$ & $\begin{array}{c}0.0047 \\
0.0061 \\
0.007\end{array}$ & 3.034 & 16.25 \\
\hline
\end{tabular}

by internal diffusion through the ash layer/solid residue product according to Eq. (9):

$$
1-3(1-x)^{\frac{2}{3}}+2(1-x)=161.97 \times e^{\frac{-26.699 \times 10^{3}}{8.314 \times T}} \times t .
$$

\subsection{Effect of interaction between factors and $R S M$}

To investigate the interactive effects and optimize the important factor affecting the copper leaching process, a series of experiments (29 runs including 10 axial points, 16 fractional factorial points, and 3 replicates at the center; $N=2^{(5-1)}+2 \times 5+3=29$ ) were designed according to Central Composite Design (CCD) implemented with Response Surface Methodology (RSM). Table 3 shows the experimental data and the responses measured for each experiment in CCD matrix selected. In order to describe the behavior of factors in the leaching process, it is first necessary to choose a suitable model. Hence, a quadratic polynomial model (Eq. (10)) was developed [35], following the removal of insignificant terms, to predict the leaching rate of copper $\left(R_{\mathrm{Cu}}\right)$ and determine the important terms. The analysis of variance (ANOVA) was also used to determine the adequacy of the model and predict the main interaction and quadratic effects of all factors as shown in Table 4. Based on the ANOVA of the quadratic regression model (Table 4), Eq. (10) which was suggested for the real relationship between the dissolution rate of copper and the significant variables is a highly significant model at a $95 \%$ confidence level $(P<0.0001)$ :

$$
\begin{aligned}
R_{\mathrm{Cu}}= & 360.3896+3.75072 \times A-0.13615 \times B \\
& -5.24442 \times C-8.63208 \times D-1.84265 \\
& \times E-0.06218 \times A \times D+0.000363 \times B \\
& \times D+0.09285 \times C \times D-0.03701 \times A^{2} \\
& +0.078741 \times D^{2}+0.013898 \times E^{2}
\end{aligned}
$$

where $A$ is sulphuric acid concentration (\%), $B$ denotes 
Table 3. Experimental factors and data in CCD matrix and measured and predicted values of copper leaching rate.

\begin{tabular}{|c|c|c|c|c|c|c|}
\hline Runs & $\begin{array}{c}\text { Sulphuric acid } \\
\text { concentration } \\
A(\%)\end{array}$ & $\begin{array}{l}\text { Stirring speed } \\
B(\mathrm{rpm})\end{array}$ & $\begin{array}{c}\text { Liquid/solid ratio } \\
\qquad C(\mathrm{ml} / \mathrm{g})\end{array}$ & $\begin{array}{c}\text { Temperature } \\
D\left({ }^{\circ} \mathrm{C}\right)\end{array}$ & $\begin{array}{l}\text { Leaching } \\
\text { time } \\
E(\min )\end{array}$ & $\begin{array}{c}\mathrm{Cu} \\
\text { recovery } \\
(\%)\end{array}$ \\
\hline 1 & 20 & 600 & 15 & 50 & 80 & 82.89 \\
\hline 2 & 10 & 400 & 15 & 50 & 80 & 77.34 \\
\hline 3 & 10 & 600 & 15 & 50 & 60 & 86.79 \\
\hline 4 & 10 & 600 & 10 & 40 & 60 & 80.61 \\
\hline 5 & 10 & 400 & 10 & 40 & 80 & 81.93 \\
\hline 6 & 10 & 600 & 15 & 40 & 80 & 73.21 \\
\hline 7 & 10 & 400 & 15 & 40 & 60 & 70.28 \\
\hline 8 & 15 & 500 & 12.5 & 35 & 70 & 77.72 \\
\hline 9 & 20 & 400 & 10 & 50 & 80 & 75.91 \\
\hline 10 & 10 & 400 & 10 & 50 & 60 & 80.47 \\
\hline 11 & 10 & 600 & 10 & 50 & 80 & 90.62 \\
\hline 12 & 15 & 500 & 12.5 & 45 & 90 & 85.48 \\
\hline 13 & 15 & 500 & 12.5 & 45 & 70 & 77.36 \\
\hline 14 & 15 & 500 & 7.5 & 45 & 70 & 81.4 \\
\hline 15 & 15 & 500 & 12.5 & 45 & 50 & 78.32 \\
\hline 16 & 20 & 400 & 10 & 40 & 60 & 77.84 \\
\hline 17 & 5 & 500 & 12.5 & 45 & 70 & 73.77 \\
\hline 18 & 15 & 500 & 12.5 & 45 & 70 & 76.13 \\
\hline 19 & 25 & 500 & 12.5 & 45 & 70 & 71.51 \\
\hline 20 & 15 & 500 & 12.5 & 55 & 70 & 90.71 \\
\hline 21 & 15 & 700 & 12.5 & 45 & 70 & 81.78 \\
\hline 22 & 20 & 400 & 15 & 40 & 80 & 73.95 \\
\hline 23 & 15 & 500 & 17.5 & 45 & 70 & 70.42 \\
\hline 24 & 15 & 500 & 12.5 & 45 & 70 & 75.75 \\
\hline 25 & 15 & 300 & 12.5 & 45 & 70 & 73.16 \\
\hline 26 & 20 & 600 & 10 & 50 & 60 & 84.27 \\
\hline 27 & 20 & 600 & 15 & 40 & 60 & 76.07 \\
\hline 28 & 20 & 400 & 15 & 50 & 60 & 72.53 \\
\hline 29 & 20 & 600 & 10 & 40 & 80 & 83.42 \\
\hline
\end{tabular}

Table 4. Analysis of variance (ANOVA) results of quadratic model to predict the leaching rate of copper.

\begin{tabular}{cccccc}
\hline Source & Sum of squares & DF & Mean square & $\boldsymbol{F}$ value & $\boldsymbol{p}$-value prob $>\mathbf{F}$ \\
\hline Model & 836.81 & 11 & 76.07 & 33.86 & $<0.0001$ \\
$A$ & 14.87 & 1 & 14.87 & 6.62 & 0.0198 \\
$B$ & 175.34 & 1 & 175.34 & 78.05 & $<0.0001$ \\
$C$ & 170.51 & 1 & 170.51 & 75.9 & $<0.0001$ \\
$D$ & 147.46 & 1 & 147.46 & 65.64 & $<0.0001$ \\
$E$ & 25.48 & 1 & 25.48 & 11.34 & 0.0037 \\
$A D$ & 38.66 & 1 & 38.66 & 17.21 & 0.0007 \\
$B D$ & 52.6 & 1 & 52.6 & 23.41 & 0.0002 \\
$C D$ & 21.55 & 1 & 21.55 & 9.59 & 0.0065 \\
$A^{2}$ & 23.04 & 1 & 23.04 & 10.25 & 0.0052 \\
$D^{2}$ & 104.28 & 1 & 104.28 & 46.42 & $<0.0001$ \\
$E^{2}$ & 51.97 & 1 & 51.97 & 23.14 & 0.0002 \\
Residual & 38.19 & 17 & 2.25 & & \\
Lack of Fit & 36.77 & 15 & 2.45 & 3.46 & 0.2468 \\
Pure Error & 1.42 & 2 & 0.71 & & \\
Cor Total & 874.99 & 28 & & & Not significant \\
Std. Dev. & 1.5 & R-Squared & 0.9564 & & \\
Mean & 78.68 & Adj R-Squared & 0.9281 & & \\
C.V. $\%$ & 1.9 & Pred R-Squared & 0.8451 & & \\
PRESS & 135.52 & Adeq Precision & 21.64 & & \\
\hline
\end{tabular}


agitation speed (rpm), $C$ depicts liquid-to-solid (L/S) ratio $(\mathrm{mL} / \mathrm{g}), D$ represents temperature $\left({ }^{\circ} \mathrm{C}\right)$, and $E$ is leaching time (min).

In order to gain the interactive effects and a better understanding of the main effects of factors on the dissolution of copper, three-dimensional response surface and interaction plots were constructed based on the suggested regression model (Eq. (10)) as shown in Figures 7 and 8. Figure $7(\mathrm{a})$-(c) indicate the 3D response surface graphs for the relationship between two factors when the other three factors were held at their center levels.

Based on Table 4, the ranking of the significant terms is as follows: $B>C>D>D^{2}>B D>$ $E^{2}>A D>E>A^{2}$. Thus, it is also observed that agitation speed and L/S ratio are the most influential factors and have a major role in the copper dissolution process. This confirms the previous results and that the transport (diffusion) process may be the ratecontrolling step in the leaching system investigated.

According to Figures 7 and 8, temperature has the most interactive effect on copper recovery. As can be seen, at high levels of temperature $\left(50^{\circ} \mathrm{C}\right)$, increasing the sulphuric acid concentration and L/S ratio results in reducing the copper leaching rate
(Figures $7(\mathrm{a})$ and $8(\mathrm{a})$ ), whereas, at low levels $\left(30^{\circ} \mathrm{C}\right)$, the increment in the acid concentration and $\mathrm{L} / \mathrm{S}$ ratio, respectively, leads to a slight increase and a sharp decline of copper recovery (Figures $7(\mathrm{c})$ and $8(\mathrm{c})$ ). The influence of agitation speed became more apparent when the temperature (Figures $7(\mathrm{~b})$ and $8(\mathrm{~b})$ ) was also high. Therefore, it can be generally concluded from the presented model and response surface plots that the copper leaching recovery depends strongly on the interaction among factors with temperature. These findings are consistent with the conclusions obtained previously.

\subsection{Optimization}

The leaching process of copper oxide ore investigated was optimized using Design Expert (DX) software (Demo v. 7.0.0, Stat-Ease, Inc.) within the experimental range studied. Table 5 implies optimum conditions suggested by Design Expert software. Three confirmation experiments were also conducted in the predicted optimum conditions to maximize copper leaching recovery, in which the average of three extra tests is reported in Table 5. The confirmatory experiments indicate the suitability and accuracy of the model. As considered, the optimal point is found to be $\sim 13 \%$

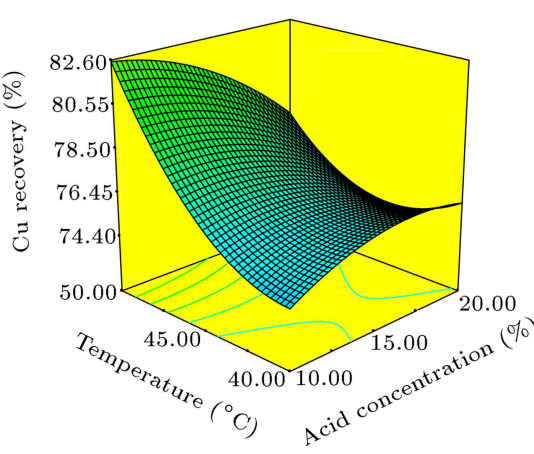

(a)

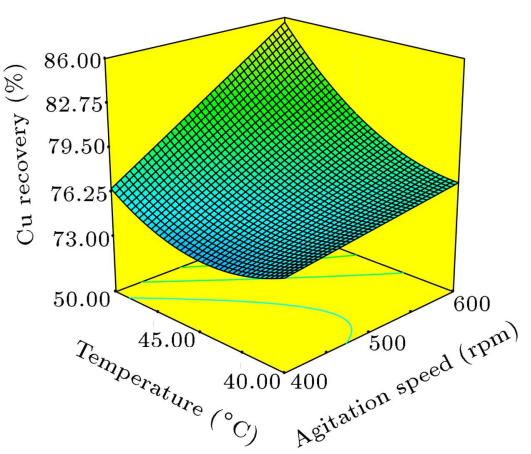

(b)

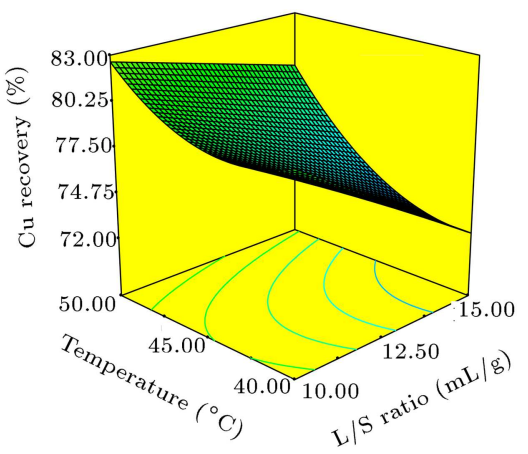

(c)

Figure 7. 3D response surface graphs: (a) Temperature and acid concentration, (b) temperature and agitation speed, and (c) temperature and liquid/solid (L/S) ratio.

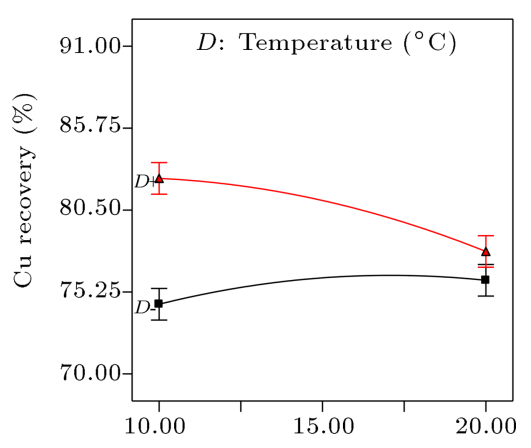

(a) Acid concentration (\%)

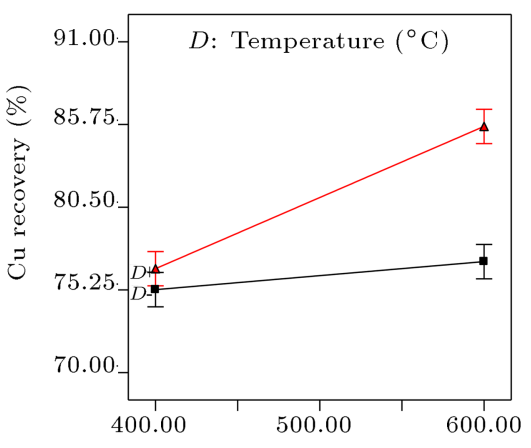

(b) Agitation speed (rpm)

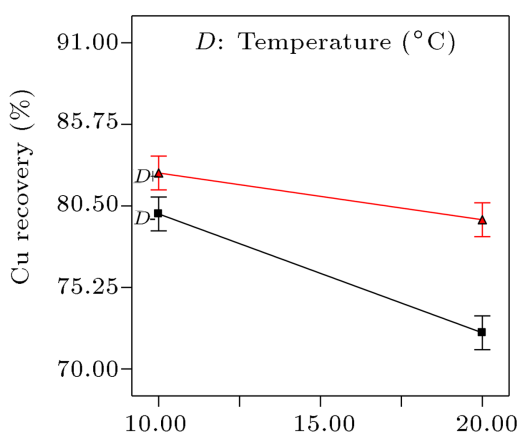

(c) $\mathrm{L} / \mathrm{S}$ ratio $(\mathrm{mL} / \mathrm{g})$

Figure 8. Interaction effect plot on Cu recovery between (a) Temperature and acid concentration, (b) temperature and agitation speed, and (c) temperature and liquid/solid (L/S) ratio. 
Table 5. The proposed levels of factors investigated to maximize the leaching rate of copper and validation of laboratory experiments.

\begin{tabular}{|c|c|c|c|c|c|c|}
\hline Factors & $\begin{array}{c}\text { Sulphuric acid } \\
\text { concentration } \\
(\%)\end{array}$ & $\begin{array}{c}\text { Stirring } \\
\text { speed } \\
(\text { rpm }) \\
\end{array}$ & $\begin{array}{c}\text { Liquid/solid } \\
\text { ratio } \\
(\mathrm{mL} / \mathrm{g}) \\
\end{array}$ & $\begin{array}{c}\text { Temperature } \\
\left({ }^{\circ} \mathrm{C}\right)\end{array}$ & $\begin{array}{c}\text { Leaching } \\
\text { time } \\
(\mathrm{min}) \\
\end{array}$ & $\begin{array}{c}\text { Cu leaching } \\
\text { rate } \\
(\%) \\
\end{array}$ \\
\hline Model & 12.92 & 600 & 10 & 50 & 78.98 & 90.36 \\
\hline Model validation & 13 & 600 & 10 & 50 & 80 & 91.09 \\
\hline
\end{tabular}

for sulphuric acid concentration, $600 \mathrm{rpm}$ for stirring speed, $10 \mathrm{~mL} / \mathrm{g}$ for liquid/solid ratio, and $50^{\circ} \mathrm{C}$ for duration of $\sim 80 \mathrm{~min}$. Under these conditions, the recovery of copper was achieved to be about $91 \%$.

\section{Conclusions}

The leaching process behavior of an Iranian copper oxide ore was investigated in three phases within the current work. In the first and second phases, the influence of various factors was investigated in detail by a classical approach of one variable at a time; subsequently, the optimal conditions for the dissolution and the interactive effects among factors were exactly determined using response surface methodology combined with a central composite design. The results indicated that agitation speed and L/S ratio were the most influential factors and had a major role in the copper dissolution; moreover, it was also an indication of the diffusion-controlled process. The dissolution rate of copper increased with increasing the temperature and leaching time, while, with increasing the agitation rate, acid concentration and liquid/solid ratio enhanced up to a certain amount and, then, decreased with a further increment. The ANOVA and 3D response surface plots were employed to determine the interactive effects between factors, and it was found that temperature had the most interactive effect on copper leaching rate. The findings confirmed the interaction among the sulphuric acid concentration, agitation speed, and liquid/solid ratio with temperature. In addition, the results showed that the maximum copper recovery $(\sim 91 \%)$ could be obtained in $\sim 13 \%$ sulphuric acid concentration, stirring rate of $600 \mathrm{rpm}$, liquid/solid ratio of $10 \mathrm{~mL} / \mathrm{g}$, temperature of $50^{\circ} \mathrm{C}$, and leaching time of $80 \mathrm{~min}$. In the third phase, the dissolution kinetics of copper oxide ore was examined according to heterogeneous model, and it was found that the dissolution rate was controlled by a diffusion process with the activation energy of $26.86 \mathrm{~kJ} / \mathrm{mol}$. A closer look indicated that the diffusion through the product layer was the ratecontrolling step during the dissolution, and the leaching kinetics can be described by the following equation:

$$
\begin{aligned}
& 1-3(1-x)^{2 / 3}+2(1-x)=161.97 \\
& \quad \times \exp \left(-26.699 \times 10^{3} / 8.314 \times T\right) \times t
\end{aligned}
$$

\section{References}

1. Armbruster, U., Martin, A., and Krepel, A. "Hydrolysis and oxidative decomposition of ethyl acetate in suband super-critical water", Appl. Catal. B. Environ., 31, pp. 263-73 (2001).

2. Arzutug, M.E., Kocakerim, M.M., and Çopur, M. "Leaching of malachite ore in $\mathrm{NH}_{3}$-saturated water", Ind. Eng. Chem. Res., 43, pp. 4118-4123 (2004).

3. Naguman, P.N. "The chemistry and kinetics of oxidized copper sulfiding by sodium thiosulfate", Russ. J. Non. Ferr. Met., 49, pp. 433-437 (2008).

4. Liu, Z.X., Yin, Z.L., Hu, H.P., and Chen, Q.Y. "Leaching kinetics of low-grade copper ore with high-alkality gangues in ammonia-ammonium sulphate solution", $J$. Cent. South. Univ. T., 19, pp. 77-84 (2012).

5. Deng, J., Wen, S., Yin, Q., Wu, D., and Sun, Q. "Leaching of malachite using 5 -sulfosalicylic acid", $J$. Taiwan Inst. Chem. Eng., 71, pp. 20-27 (2017).

6. Haghighi, H.K., Moradkhani, D., Sedaghat, B., Rajaie Najafabadi, M., and Behnamfard, A. "Production of copper cathode from oxidized copper ores by acidic leaching and two-step precipitation followed by electrowinning", Hydrometallurgy, 133, pp. 111-117 (2013).

7. Bingol, D. and Canbazoğlu, M. "Dissolution kinetics of malachite in sulphuric acid", Hydrometallurgy, 72, pp. 159-165 (2004).

8. Crundwell, F.K. "The mechanism of dissolution of minerals in acidic and alkaline solutions: Part III. Application to oxide, hydroxide and sulfide minerals", Hydrometallurgy, 149, pp. 71-81 (2014).

9. Ata, O.N., Colak, S., Ekinci, Z., and Copur, M. "Determination of the optimum conditions for leaching of malachite ore in $\mathrm{H}_{2} \mathrm{SO}_{4}$ solutions", Chem. Eng. Technol., 24, pp. 409-413 (2001).

10. Shayestehfar, M.R., Karimi Nasab, S., and Mohammadalizadeh, H. "Mineralogy, petrology, and chemistry studies to evaluate oxide copper ores for heap leaching in Sarcheshmeh copper mine, Kerman, Iran", J. Hazard. Mater., 154, pp. 602-612 (2008).

11. Habbache, N., Alane, N., Djerad, S., and Tifouti, L. "Leaching of copper oxide with different acid solutions", Chem. Eng. J., 152, pp. 503-508 (2009). 
12. Shabani, M., Irannajad, M., and Azadmehr, A. "Investigation on leaching of malachite by citric acid", Int. J. Min. Met. Mater., 19, pp. 782-786 (2012).

13. Deng, J., Wen, S., Deng, J., Wu, D., and Yang, J. "Extracting copper by lactic acid from copper oxide ore and dissolution kinetics", J. Chem. Eng. Jpn., 48, pp. 1-7 (2015).

14. Ekmekyapar, A., Clolak, S., Alkan, M., and Kayadeniz, I. "Dissolution kinetics of an oxidized copper ore in water saturated by chlorine", J. Chem. Technol. Biotechnol., 43, pp. 195-204 (1988).

15. Yartaşi, A. and Copur, M. "Dissolution kinetics of copper (ii) oxide in ammonium chloride solutions", Miner. Eng., 9, pp. 693-698 (1996).

16. Ekmekyapar, A., Oya, R., and Künkül, A. "Dissolution kinetics of an oxidized copper ore in ammonium chloride solution", Chem. Biochem. Eng. Q., 17, pp. 261-266 (2003).

17. Bingol, D., Canbazoğlu, M., and Aydoğan, S. "Dissolution kinetics of malachite in ammonia/ammonium carbonate leaching", Hydrometallurgy, 76, pp. 55-62 (2005).

18. Calban, T., Colak, S., and Yeşilyurt, M. "Optimization of leaching of copper from oxidized copper ore in $\mathrm{NH}_{3}-$ $\left(\mathrm{NH}_{4}\right)_{2} \mathrm{SO}_{4}$ medium", Chem. Eng. Commun., 192, pp. 1515-1524 (2005).

19. Liu, W., Tang, M.-T., Tang, C.-B., He, J., Yang, S.H., and Yang, J.-G. "Dissolution kinetics of low grade complex copper ore in ammonia-ammonium chloride solution", Trans. Nonferr Metals. Soc. China., 20, pp. 910-917 (2010).

20. Ekmekyapar, A., Aktaş, E., Künkül, A., and Demirkiran, N. "Investigation of leaching kinetics of copper from malachite ore in ammonium nitrate solutions", Metall. Mater. Trans. B., 43, pp. 764-772 (2012).

21. Künkül, A., Gülezgin, A., and Demirkiran, N. "Investigation of the use of ammonium acetate as an alternative lixiviant in the leaching of malachite ore", Chem. Ind. Chem. Eng. Q., 19, pp. 25-34 (2013).

22. Wu, D., Wen, S., Yang, J., Deng, J., and Jiang, L. "Dissolution kinetics of malachite as an alternative copper source with an organic leach reagent", J. Chem. Eng. Jpn., 46, pp. 677-682 (2013).

23. Ekmekyapar, A., Demirkıran, N., Künkül, A., and Aktaş, E. "Leaching of malachite ore in ammonium sulfate solutions and production of copper oxide", Braz. J. Chem. Eng., 32, pp. 155-165 (2015).

24. Mao, Y., Deng, J., Wen, S., Fang, J., and Yin, Q. "Recovering copper from volcanic ASH by $\mathrm{NH}_{3} \cdot \mathrm{H}_{2} \mathrm{O}-$ $\mathrm{NH}_{2} \mathrm{COONH}_{4}$ ", Russ. J. Non-ferrous Metals., 57, pp. 533-543 (2016).
25. Tanda, B.C., Eksteen, J.J., and Oraby, E.A. "An investigation into the leaching behaviour of copper oxide minerals in aqueous alkaline glycine solutions", Hydrometallurgy, 167, pp. 153-162 (2017).

26. Deng, J., Wen, S., Deng, J., and Wu, D. "Extracting copper from copper oxide ore by a zwitterionic reagent and dissolution kinetics", Int. J. Miner. Metall. Mater., 22, pp. 241-248 (2015).

27. Sun, X., Chen, B., Yang, X., and Liu, Y. "Technological conditions and kinetics of leaching copper from complex copper oxide ore", J. Cent. South Univ. Technol., 16, pp. 936- 941 (2009).

28. Azizi, A. and Seyed Ghasemi, S.M. "A comparative analysis of the dissolution kinetics of lead from low grade oxide ores in $\mathrm{HCl}, \mathrm{H}_{2} \mathrm{SO}_{4}, \mathrm{HNO}_{3}$ and citric acid solutions", Metall. Res. Technol., 114, p. 406 (2017). DOI: org/10.1051/metal/2017014.

29. Seyed Ghasemi, S.M. and Azizi, A. "Alkaline leaching of lead and zinc by sodium hydroxide: kinetics modeling", J. Mater. Res. Technol. (2017). DOI: org/10.1016/j.jmrt.2017.03.005 (In Pressed).

30. Espiari, S., Rashchi, F., and Sadrnezhaad, S.K. "Hydrometallurgical treatment of tailings with high zinc content", Hydrometallurgy, 82, pp. 54-62 (2006).

31. Levenspiel, O., Chemical Reaction Engineering, 3rd Ed. John Wiley \& Sons, New York (1999).

32. Wang, R., Tang, M., Yang, S., Zhagn, W., Tang, C., He, J., and Yang, J. "Leaching kinetics of low grade zinc oxide ore in $\mathrm{NH}_{3}-\mathrm{NH}_{4} \mathrm{Cl}-\mathrm{H}_{2} \mathrm{O}$ system", J. Cent. South. Univ. Technol., 15, pp. 679-83 (2008).

33. Adebayo, A.O. and Olasehinde, E.F. "Leaching kinetics of lead from galena with acidified hydrogen peroxide and sodium chloride solution", Trans. Inst. Min. Metall., Sect. C., 124, pp. 137-142 (2015).

34. Lee, I.H., Wang, Y.-J., and Chern, J.-M. "Extraction kinetics of heavy metal-containing sludge", J. Hazard. Mater., 123, pp. 112-119 (2005).

35. Azizi, A. and Ghaedrahmati, R. "Optimizing and evaluating the operational factors affecting the cyanide leaching circuit of the Aghdareh gold processing plant using a CCD model", Proc. R. Soc. A., 471(2184), p. 20150681 (2015). DOI: $10.1098 /$ rspa.2015.0681.

\section{Biographies}

Behrooz Bayati obtained his BSc degree in Mining Engineering (2014) from Birjand University of Technology. He then received MSc degree in Mineral Processing Engineering from Shahrood University of Technology in 2017.

Asghar Azizi received his BSc degree in Mine Exploration Engineering (2005) from Shahrood University of Technology and his MSc degree in Mineral Processing Engineering (2007) from Yazd University, Iran. He 
attained his $\mathrm{PhD}$ degree from Shahrood University of Technology, Shahrood, Iran in 2013. He is currently an Assistant Professor in Faculty of Mining, Petroleum and Geophysics, Shahrood University of Technology. His research interests mostly include hydrometallurgy, electrochemistry in mineral processing systems and optimization and modeling.
Mohammad Karamoozian is currently an Associate Professor in Faculty of Mining, Petroleum and Geophysics, Shahrood University of Technology. He obtained his $\mathrm{PhD}$ degree from Shahrood University of Technology, Shahrood, Iran in 2008. His research interests mostly include flotation, grinding, and optimization and modeling of mineral processing systems. 